Peer-Reviewed Article

ISSN: 2162-3104 Print/ ISSN: 2166-3750 Online

Volume 6, Issue 1 (2016), pp. 1-13

(C) Journal of International Students

http://jistudents.org/

\title{
International Students' Social Network: Network Mapping to Gauge Friendship Formation and Student Engagement on Campus
}

\author{
Susannah McFaul \\ Georgia Institute of Technology (USA)
}

\begin{abstract}
Addressing the importance of international student engagement on campus and creating friendships with host-country nationals during their time abroad, this small-scale study explores the question of, "Are there trends in how or through what means international students are making connections with co-national, multi-national, or host-national students?" Semistructured, qualitative interviews, data collection, social network analysis and a data-representative social network diagram were used to explore this question. Understanding these trends can help with developing student programming that encourages friendship making, cross-cultural workshops, or even provide the foundation and reasoning to strengthen support systems for international students.
\end{abstract}

Keywords: social network analysis, cross-cultural friendships, international student engagement

The number of international students studying abroad and completing degrees in the United States continually rises each year. During the academic year 2013-2014, a record high of 886, 052 international students were enrolled in institutions across the country (Institute of International Education, 2014). International educators and institutes of higher education have a stake in increasing the international student populations on campus because of the positive economic impact as well as internationalization efforts and emphasis on diversity in universities and colleges. Reported 
student satisfaction rating is an important component in international student retention as well as international student recruitment and enrollment growth. The literature surrounding international student experiences, integration, cross-cultural learning, communication, and satisfaction is robust, particularly in the academic realms of the cross-cultural communication and higher education fields.

In assessing the current literature, trends of study emerge including the tendencies of international students to form more connections with students from the same country or culture or other international students and the value of building friendships and relationships with students that originate in the country of study, or domestic students. Additionally, extant literature reveals that co-curricular and/or on-campus participation and engagement is an important contributor to international student experiences. Further, an emerging approach to the study of international students on American campuses utilizes the concepts of social network theory and social network analysis.

This study explores existing research within the following frames: international students' co-national, multi-national and host-national relationship formations, the impact of co-curricular and on-campus socialization of international students' study abroad experiences, and the use of social network theory concepts in study and the use of social network analysis as a tool to research international student populations in higher education. Subsequently, it seeks to answer a new research question: Are there trends in how or through what means international students are making connections with co-national, multi-national, or host-national students? Semi-structured, qualitative interviews, data collection, social network analysis and a data-representative sociogram were used to investigate the research question. Investigating how initial friendships and connections are being made is a significant contribution because in order to address the commonly asked question of, "how can we help international students become more engaged on campus and make more friends?” it is important to first understand if trends exist in how students are already connecting with others. This is particularly relevant if there are trends in how international students are connecting with American, or host-national students. This information has potential implications for higher education administration or those who are tasked with international student programming, engagement on campus, or internationalization efforts.

\section{LITERATURE REVIEW}

Much of the academic literature that discusses international student relationships, connections, and friendships adopts Bochner, McLeod and Lin's (1977) vocabulary that categorizes these relationships into three 
distinct network classifications of co-national, multi-national, and hostnational connections (as cited in Hendrickson, Rosen \& Aune, 2011). The terminology of monocultural ties, multicultural ties, and bicultural ties is also used to differentiate the types of friendships formed by international students (Rienties, Heliot \& Jindal-Snape, 2013; Gomez, Urzua \& Glass, 2014; Glass \& Westmont, 2013). In this study and analysis, the vernacular of co-national networks is adopted to explain contacts with other students originating from the same national background. Multi-national networks means connections with other international students, not from the student's own country or nationality. Host-country national network is used when referencing contact with students from host country or "domestic" students. Examinations of international students studying abroad have largely revealed an inclination of international students to form social networks that principally include co-national students and then secondarily include multinational students (Rienties et al., 2013; Montgomery \& McDowell, 2009; Hendrickson et al., 2011; Rienties et al., 2013; Neri \& Ville, 2007). The prevailing understanding is that relationships with students from the same country or with shared nationality form friendships and relationships more easily, and cultural similarities along with shared experiences of being in a foreign culture bring the students together (Montgomery \& McDowell, 2009; Rienties et al., 2013; Glass \& Westmont, 2013).

Although the collectiveness of nationalities in international student friendship formation is widely acknowledged throughout the literature, differences in research results and assessment reveals a distinct split in interpretation about whether students with mostly co-national or multinational networks contribute positively or negatively to an individual's acculturation into the United States and overall satisfaction with study abroad experience. For example, Montgomery and McDowell (2009) and Glass and Westmont (2013) approach the tendency for international students to build co-national communities from a positive perspective and highlight the networks ability to be a support system. Montgomery and McDowell (2009) extend this notion and suggest that that academic discourse surrounding international students' inclination to make friends based on cultural likeness is largely negative and challenges the idea that students' networks need to include strong host-country national connections in order to learn and have a positive experience at a university outside their own home country. However, Hendrickson et al.'s (2011) survey of 86 international students studying at a university in Hawai'i measured students' social connectedness, homesickness and contentment, and satisfaction with life. The results of the survey paired with data collected for a friendship network grid, revealed that those students with more co-national connections scored much lower on the scale for social connectedness and 
overall satisfaction while studying at the university (Hendrickson et al., 2011). Glass and Westmont (2013) introduce the notion that the support of a strong co-national or multi-national network can actually be a catalyst for students to engage with host students by providing the confidence to explore an unfamiliar culture.

Along similar lines, the literature includes research into the value of international students' bridging links with host-national students and the value these relationships bring to students' social networks (Hendrickson et al., 2011; Ramsay, Jones \& Barker, 2007; Gomez, Urzua \& Glass, 2014), as well as the difficulty that international students encounter in making those friendships with host students (Rienties et al., 2013; Neri \&Ville, 2008). Interestingly, Granovetter's (1973) concepts of the importance in the creation and maintenance of weak ties within a network were applied to international students and host students. Both Ramsay et al. (2007) and Hendrickson et al.'s (2011) work reiterate that weak ties with host students provide the possibility of sharing practical, locally-specific information with international students. Hendrickson et al. (2011) notes the importance of a variation in the types of connections within a network and provides the field with data based on exhaustive lists of student participation, which recognizes the importance of weak ties. The authors state, "theoretically having a variety of social contacts should give individuals access to different kinds of social resources and those with little variation could be hindered in that process" (Hendrickson et al., 2011, p. 290). Coinciding with the evidence that host student friendships are valuable, Gomez et al.’s (2104) online study and survey of 356 students at a U.S. mid-Atlantic university, a $41 \%$ response rate yielded results indicating that one of the two most important factors in a student's ability to socially adjust was building relationships with host-nationals and having a strong host network. In assessing the existing literature on the topic of co-national, multi-national, and host-national connection, interpretations of the results can be both positive and negative. Although differences emerge, two main themes are dominant in the literature: (1) international students tend to have networks that include more co-national and multi-national links and (2) relationships with host-country nationals, both strong and weak connections, are significant to students' adjustment and successful acculturation to the university community, but harder for international students to initiate and maintain.

When approaching topics of international students on college campuses in the United States, researchers and practitioners utilize many terms in referring to their cultural transition including assimilation, acculturation, belongingness, adjustment, transition, and adaptation (Gomez et al., 2014; Gallagher, 2013; Glass \& Westmont; 2014; Hommes, Rienties, de Grave, 
Bos, Schuwirth, \& Scherpbier, 2012; Neri \& Ville, 2008; Ramsay et al., 2006). These terms are used in accordance to the authors' definition and explanation of the terms and their individual research goals. For example, Gomez et al. (2014) states that successful acculturation encompasses international students' ability to engage socially and interact with other students. Meanwhile, Gallagher's (2013) focus is on the student's ability to both communicate in a second, or host language, and do so with confidence, because that component of international students' experience relates to a positive adaptation to life in the United States. Glass and Westmont (2014) approach this topic a theoretical framework that uses resilience-based models and investigate by looking at factors that inhibit successful academic and social performance while students are residing in the United States. Despite the varying terms, the literature seems to reveal that international students' successful adjustment to life in the United States and on American college/university campuses is multi-faceted and includes successful academic performance (Hommes et al., 2012; Neri \& Ville, 2008), the ability to communicate with host-national and multi-nationals through the English language (Gallagher, 2013), engagement in leisure and socializing rituals (Gomez et al., 2014), negating factors and risks that could negatively impact their cultural transition (Glass \& Westmont, 2014), and building communities and social networks (Neri \& Ville, 2008; Rienties et al., 2013; Montgomery \& McDowell, 2009). An important consideration, too, is that adapting successfully to college and life in the Unites States requires crosscultural understanding both about the international students' own culture through self-reflection while in the host country, as well as cross-cultural learning from members of the host-country community (Hendrickson et al., 2011; Ramsay, Jones \& Barker, 2007; Gomez et al., 2014). Although this research study is not intended to gauge or measure students' acculturation, acclimation, or connectedness, the use of the varied terminology and definitions is important to note because the literature reveals that social networks and friendship formations have an impact on the success of international students' experiences. This understanding is a sustaining reason behind the need to look at student friendship networks through a variety of lenses, including investigating how and through what means these connections are formed.

International student engagement in co-curricular and on-campus socialization activities is another thematic topic in the literature. International student involvement in activities that extend outside of the classroom has been shown to have a positive impact on international student sense of belonging and social adjustment (Glass \& Westmont, 2014; Gomez et al., 2014; Neri \& Ville, 2008) as well as to contribute positively to learning (Gomez et al., 2014; Hommes et al., 2012). For example, Neri and 
Ville (2008) asked international student participants to complete surveys that, in part, measured the amount of time spent with friends in informal, social engagement and discovered that on average, the 173 participants, spent approximately 11 hours per week with friends in this capacity and also revealed a large quantity of students reported being involved in university clubs and were engaged in clubs outside of school as well. Through these co-curricular avenues, including club participation, work, and volunteer activities, international students build social networks that extended to people outside of their own culture (Neri \& Ville, 2008).

Correspondingly, Hommes et al. (2011), found that social networks contributed positively to learning objectives and asserts that these more informal social mechanisms such as friendships and reciprocal information sharing between students deserves a larger consideration because of the contributions to academic learning, and that the formal classroom learning is not the only relevant component in education. Gomez et al. (2014) echoes Hommes et al. (2014) but extends the findings to international students and focuses on topics of leisure, sports, and recreational activities. Within this research, Gomez et al. (2014) addresses the cultural separation between international students and host-national students in the participation in and appreciation of sports and leisure. As international student adjust, they were found to become more open to leisure and receptive to using their time for this reason. The establishment of a social network combined with leisure activities are significant predictors to a smooth transition and satisfaction at the university (Gomez et al., 2014). The cultural differences regarding the way international students and host-country students divide their time, approach leisure and on-campus socialization opportunities is an important topic, one that has the potential to help us understand reasons why connections between these groups is difficult.

The literature studying social aspects of international students has many ranges of topics, covering friendship making, the strength of connection types within networks, the value or inhibiting nature of co-national, multinational, and host-national ties, and cross-cultural classroom learning, as examples. Several articles and literature exploring these areas have utilized social network theory concepts as framework to their analysis and/or added social network analysis to visualize the results (Montgomery \& McDowell, 2008; Hommes et al., 2012; Gomez et al., 2014; Hendrickson et al., 2011; and Rienties et al., 2013). Both Montgomery and McDowell (2008) and Rienties et al. (2013) utilized a blend of qualitative measures such as semistructured interviews and focus groups, and a combination of analysis of social networks that included a graphical representation. Rienties et al. (2013) specifically uses these tools to study how international and host students interact and build networks within a large classroom over time, and 
assert that social network analysis is an innovative approach and the graphical analysis is useful in showcasing results. Both Hendrickson et al. (2011) and Hommes et al. (2012) utilize ego-centric network analysis, which centralizes the experiences of the individual student, and as Hommes et al. (2012) explains, "the network approach views individuals as interdependent, taking into account a person's resources, information flow, and relationships" (p.744).

Additionally, the studies that use social network theory and analysis provide examples of the ways it can be used with both small samples and larger ones. For instance, Montgomery and McDowell (2008) created a network diagram to map the patterns of relationships between seven participants in a small international student group over a span of two days. On the other hand, Rienties et al.'s (2013) visual social network graph represented data from 191 international students from 34 cultural backgrounds and showed the progression of connections within the closed network over a longer span of time, 11 weeks. These two examples establish the multiplicity of ways social network theory concepts and graphical analysis can be useful in research. These sources of literature show the ways that social network theory and social network analysis and sociogram/ maps are tools to enhance qualitative or quantitative information, especially when examining networks and relationships between groups. They afford an opportunity to visualize the data and make assessments and discoveries that would not otherwise be possible. In conclusion, literature regarding international student socialization often categorizes these links into conational, multi-national and host-national nodes and offers different interpretations about the value of having these types of connections in one's network. Additionally, some authors support the value of inquiry into the co-curricular and on-campus involvement of students. A wealth of research has been conducted and knowledge has been gained by employing social network theory principles, and social network analysis.

\section{RESEARCH METHOD}

Data collection for this sample group includes two components: an informal interview or meeting with students in the Office for International Students and Scholars suite on campus to explain the nature of the study and give instructions for completing a hand-written survey/ handout. The survey is the means for gathering qualitative information. The short, verbal session was chosen for two reasons: first, given the different levels of English proficiency, an in-person chat helps to ensure understanding of what is being asked. Second, this method allows for the researcher to look over 
responses, probe for clarifications, and better gauge usable responses as written on the survey.

The research plans involved gathering the data from participants, and then identifying categories of where/how students are meeting. Using those categories, a social network map/sociogram was created showing trends in international student study participants' social networks, and where or how they initially met friends, using the identified categories. In this study, the term friend is used and was explained to participants as a social connection with another individual with whom they regularly communicate or engage. The map also shows whether the connection is a co-national, multi-national, or host-national one. In addition to the creation of the social network map, graphical representation, this study synthesized the information gathered into an analysis, highlighting any trends or information gained. Like other aforementioned researchers, social network theory principles were used to inform the interpretations of the findings and in the social network analysis. Doing so showcases any trends in friendship formations that trace back to certain on-campus offices, social events, residences, class, or other avenues.

\section{Participants}

This study examines international students studying at DePaul University in Chicago, IL. The international student term, in this context, refers to a student who has entered the United States via a short-term visa classification of F-1. These students were actively enrolled at the time, maintaining lawful status, and their degree levels vary to include English Language program, Bachelor's degrees and Master's degrees. Because the students in the study are working towards program completion in the United States, and hold an F-1 Student Visa, the term international students is used, as opposed to the term study abroad students. This distinction is important, too, because the label "study abroad students" is often used to describe American students traveling to destinations and studying outside of the United States in journals and publications. The 16 participants for this small-scale study range in country of nationality and include: China, Philippines, United Kingdom, South Korea, France, United Arab Emirates, and Saudi Arabia. Volunteer participation was recruited at the Office for International Students and Scholars student events during the spring 2014 quarter including a social lunch, student organization activity, and employment information session.

\section{RESULTS}

The interview data collected from the 16 international students regarding where or how they initiated the friendships listed on the survey was 
reviewed and 10 categories were created based on the patterns of the answers and include the following: on-campus departmental events, oncampus Career Center, religious/ spiritual organizations, volunteer opportunity, recreation-other, Office for International Students and Scholars' events, work, housing/ residence, on-campus student organizations, and class. The categories reveal specific trends in how the participants are creating connections on-campus and in the community. Once the categories were determined, the connections or links between the student participants and their friends were mapped on a social network map that divided the friendships based on how those people met originally and were color-coded to indicate friendship type: multi-national, co-national, or host-national. For example, participant 1 met a host-national (American) friend in class, and this was indicated on the diagram by connecting the two links in red and under the category of Class. The social network diagram or sociogram was used to clearly visualize the results as indicated on the student completed form/survey. The diagram visualization highlights a number of the results including the most popular categories through which the international student research participants made friends, the most prevalent being class, housing/ residence, and on-campus student organizations. Significantly, the map reveals the friendship types that were generated through these categories. For example, international student participants' friendships made through class are varied and include multinational, host-national, and co-national. Interestingly, the leading friendship types made in class were with students from their own country. Similarly, the map reveals that international student participants are making friends through their living arrangements, and, further, these friendships tend to be either host-national or co-national, with more co-national friends made than host-national. Connections made through on-campus student organizations are revealed in the network map as being diverse, with some host, multi, and co-national friendships represented. Similarly, the connections made through the categories of religious and spiritual organizations as well as through work also included a variety of friendship types. The friendships generated from the Office for International Students,' however, were predominantly multi-national in nature, and did not include the variety of other categories.

Aside from the type of friendships and the means through which the friends met, the results and diagram include friendships established through another friend. For example, international student \#8 (as represented on map) met a co-national friend through housing and that friend then introduced the participant to two other co-national friends. Including these connectors was important so that the researcher could trace friendships made through others back to the original meeting point. Further these 
"connector" friends provide insight into how networks expand by one person introducing another, and consequently opening up new links and potential links.

In looking at the constructed social network map and research results and revisiting the research question of, are there trends in how international students' are making friendships and expanding their social networks?, the project reveals that, in fact, there are distinct categories in which the student participants' initially met and subsequently developed friendships.

\section{DISCUSSION AND CONCLUSIONS}

This research can be used to draw conclusions about the tendencies of international students to have social networks that are made up of people from a similar cultural background or other international students. It also speaks to the role of engagement in on-campus and co-curricular activities and socialization on international friendship formation and friendship network expansion and, lastly, this research provides another example of the usefulness of social network theory and social network maps or sociograms in this context.

Figure1: International Student Friendship Formation Network Diagram

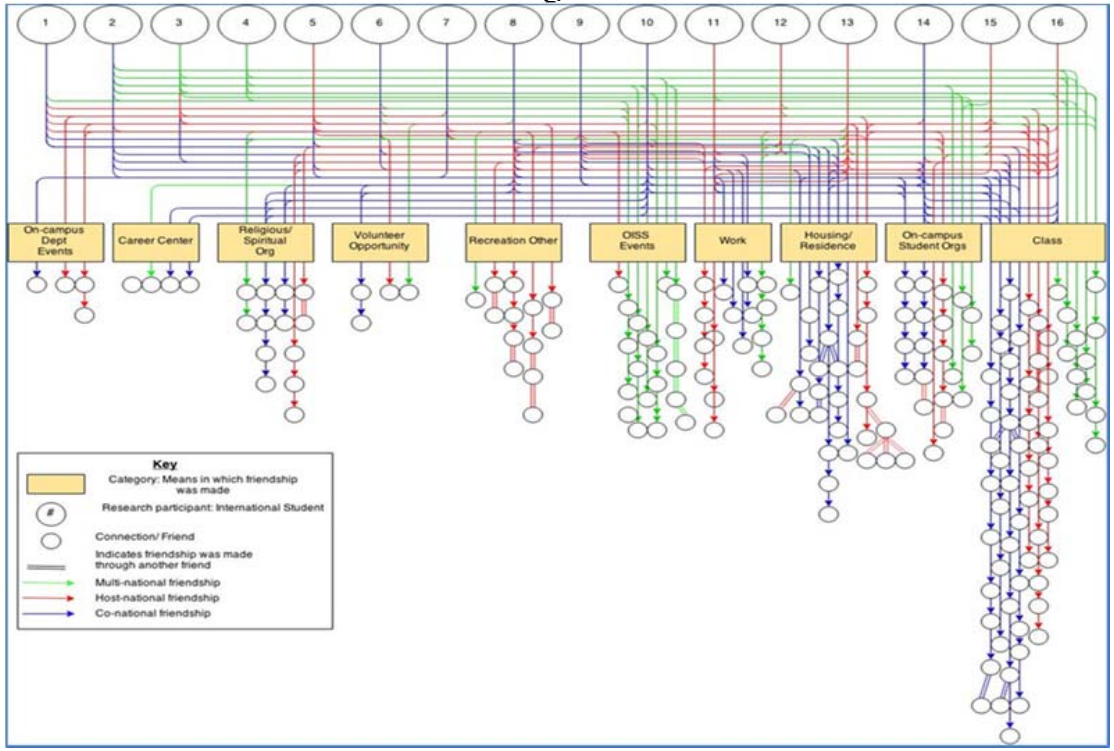


Upon review of the data and findings, this research supports the extant literature and found that the international student participants in this study have a large proportion of friends from their own country or culture, and higher number of co-national friendships compared to host-national ones. Even in the classroom and residential setting, the international student participants bonded with those from the same county, and formed conational connections at a higher rate than the others. Like Rienties et al. (2013) Montogomery and McDowell, (2009) Hendrickson et al. (2011), Rienties et al. (2013), and Neri and Ville (2007), this study points out this tendency but also adds an important dimension. Even though more conational and multi-national student friendships were reported, this research shows that host-national friendships are being made in some of the same ways, like in the case of class, work, and residence and housing engagement. It also shows that these friendships are made by involvement on campus, specifically in situations that elicit meeting more than once such as class, religious or spiritual organizations, in housing, or in student organizations and involve repetitive meetings of the same individuals.

Singular events showed fewer friendships developed, perhaps because of the lack of repetition, like in the case of other departmental events. Friends were made in context of socialization, including events, religious/ spiritual organization involvement, recreation, and class. This finding supports the literature that highlights the importance of socialization skills, engagement in leisure, and engagement in on-campus and involvement in the successful experiences of students (Glass \& Westmont, 2014; Gomez et al., 2014; Neri \& Ville, 2008; Hommes et al., 2014).

\section{IMPLICATIONS}

Higher education institutions that host international students can utilize this information or this type of research in a myriad of ways, particularly when considering ways to assess and learn about student engagement on campus and whether their students are connecting with others. For example, international student offices could utilize it as evidence that cross-cultural engagement or internationalization efforts are working. In this particular study, DePaul Office for International Students and Scholars' events such as Global Coffee Hour and New Student Orientation came up several times as being events in which students met and initiated conversation and then friendship. Oftentimes, the lasting effects of events and programming efforts meant to engage seem difficult to measure, but utilizing data collection and social network mapping can be one assessment strategy. Additionally, the data reveals many friendships are made in classrooms, so this could indicate the need to partner with professors and academic units to learn the impact of classroom dynamics and strategize ways to be inclusive 
to international students and use the curriculum to help build connections between students. Similarly, offices may look at the residence and housing category and decide to partner with residence life to train student leaders in cross-cultural topics or, if the goal is for international students to make friends with Americans, this data can be used to show the trends in student friendships being made with host-nationals through housing. This type of research can be a roadmap for partnerships or even justifications for continuing programming efforts to engage international students. A "hey look, it is working!" method that is new and extends beyond traditional evaluations and survey questions and includes longer term positive implications.

This study has many potential implications and also provides ideas for areas of research. For instance, a more in-depth or expansive study looking at how international students create connections after arriving in the United States would add to the extant literature. Also, this study indicated that the role of repetition in meeting the same group of students more than once had a positive impact on their ability to build friendships within the determined category. This notion of repetitive communication opportunity as an influence of social network development is another potential avenue of research that could be explored in the future.

Because this was a small-term study, a limitation includes that participants were only asked to list up to 15 friends made since arriving in the United States. Because this was not an exhaustive list, the potential for uncovering weak links and ties within the students' social networks was outside of the parameter of this study. Another important limitation for consideration in future, related research is that this study did not differentiate between the amount of time students have been in the United States and so does not include how the results vary depending on elapsed time spent at the university or in the United States. This could be added in future studies and specific populations could be selected and even a longitudinal study could be done to show the social network growth over time.

\section{REFERENCES}

Bochner, S., McLeod, B., \& Lin, A. (1977). Friendship patterns of overseas students: Functional model. International Journal of Psychology, 12, 277-294.

Gallagher, C. (2012). Willingness to communicate and cross-cultural adaptation: L2 communication and acculturative stress as transaction. Applied Linguistics, 34(1), 53-73.

Glass, C., \& Westmont, C. (2013). Comparative effects of belongingness on the academic success and cross-cultural interactions of domestic and 
international students. International Journal of Intercultural Relations, 38, 106-119.

Gomez, E., Urzua, A., \& Glass, C. (2014). International student adjustment to college: Social networks, acculturation, and leisure. Journal of Park and Recreation Administration, 32(1), 7-25.

Granovetter, M. (1973). The strength of weak ties. American Journal of Sociology, 78(6), 1360-1380.

Hendrickson, B., Rosen, D., \& Aune, R. (2011). An analysis of friendship networks, social connectedness, homesickness, and satisfaction levels of international students. International Journal of Intercultural Relations, 35, 281-295.

Hommes, J., Rienties, B., de Grave, W., Bos, G., Schuwirth, L., \& Scherpbier, A. (2012). Visualising the invisible: a network approach to reveal the informal social side of student learning. Adv in Health Sci Educ, 17, 743-757.

Institute of International Education. (2013). International students in the U.S. 2012-2013. Open Doors 2013 Report on International Educational Exchange. Retrieved from http://www.iie.org/opendoors

Montgomery, C., \& McDowell, L. (2009). Social networks and the international student experience: An international community of practice? Journal of Studies in International Education, 13(4), 455-466.

Neri, F., \& Ville, S. (2007). Social capital renewal and the academic performance of international students in Australia. The Journal of SocioEconomics, 37, 1515-1538.

Ramsay, S., Jones, E., \& Barker, M. (2007). Relationship between adjustment and support types: Young and mature-aged local and international first year university students. Higher Education, 54, 247265.

Rienties, B., Heliot, Y., \& Jindal-Snape, D. (2013). Understanding social learning relations of international students in a large classroom using social network analysis. Higher Education, 66, 489-504.

Kuo, W. H., \& Tsai, Y. M. (1986). Social networking, hardiness and immigrant's mental health. Journal of Health and Social Behavior, 27, 133-149. doi:10.2307/2136312

SUSANNAH MCFAUL, M.A. Multicultural Communication, is an international educator. She serves as the International Special Programs Advisor at Georgia Institute of Technology and her research interests include cross-cultural friendships and engaging international students on American college campuses. 